\title{
The effects of different types of retrieval cues on the recall of names of famous faces
}

\author{
J. RICHARD HANLEY \\ University of Liverpool, Liverpool, England \\ and \\ ELAINE S. COWELL \\ Newcastle Polytechnic, Newcastle upon Tyne, England
}

\begin{abstract}
The present study investigated the effects of cues on subjects' abilities to retrieve the names of famous faces that they had previously been unable to recall. In Experiment 1 subjects were presented with a second photograph of the celebrity, or biographical information about the celebrity, or the celebrity's initials. Each type of cue produced a quite different pattern of recall. Biographical information was least likely to elicit the name when the subject already knew the celebrity's occupation, and most likely when subjects found the face familiar only. Conversely, initials were more likely to elicit the name when the occupation was already known than when the face was at first found unfamiliar or familiar only. Rather surprisingly, no significant differences were observed when a new photograph was used as a cue. In Experiment 2, the effects of a new photograph were compared with a condition in which the same photograph was presented twice. A new photograph was beneficial when subjects had previously found the face unfamiliar and when they found the face familiar only, but not when they knew the occupation. It is argued that these, as well as other aspects of the results, generally support the view that successive, but distinct stages are involved in face recognition, consistent with the model put forward by Bruce and Young (1986).
\end{abstract}

The purpose of the research reported here was to provide evidence relevant to the model of face recognition put forward by Young and his associates (Bruce \& Young, 1986; Hay \& Young, 1982). According to this model, every face that one knows is mentally represented by its own face recognition unit, which is abstract in the sense that it responds regardless of the view of the face that is seen. In order to name a particular face successfully, the perceiver must first activate the appropriate recognition unit in memory. Once this has occurred, the face will feel familiar to the perceiver, and it will become possible to access the contextual or "semantic" information that is associated with the person, such as his/her occupation or where he/she is most frequently encountered. Success in accessing contextual information from the face recognition unit is by no means guaranteed, however, as in the situation where a face seems familiar, but one is unable to remember any specific information associated with the person.

Once contextual information has been accessed, it then becomes possible to enter the final stage of face recogni-

\footnotetext{
We thank Andy Young, Norma Pearson, and Chris Dracup for their assistance at various stages of this project. In addition, we would like to express our gratitude to James Bartlett, Vicki Bruce, and an anonymous reviewer for their constructive criticisms of and comments on a previous version of this manuscript. Requests for reprints should be sent to J. R. Hanley, Department of Psychology, University of Liverpool, Eleanor Rathbone Building, P.O. Box 147, Liverpool L69 3BX, England.
}

tion and successfully name the face. This is another point at which the process can break down, as in the situation where one can retrieve a great deal of information associated with a familiar face but simply cannot remember the name. In summary, the model states that a person's name does not have a direct link to the face recognition unit; the name can be retrieved only indirectly via contextual or semantic information associated with the unit. The processes of activating a unit, accessing contextual information, and retrieving the name are successive but distinct stages in face recognition, and failure at any one of them will result in failure to produce the person's name.

Many of these ideas about face recognition are not unique to the model of Hay and Young (1982) and Bruce and Young (1986). For instance, on the basis of their research into prosopagnosia, Damasio, Damasio, and Van Hoesen (1982) and Tranel and Damasio (1985) suggested the existence of a facial "template" system, which contains a separate template for each face that one knows. Moreover, the template "holds the lock" to contextual information associated with the person, but does not store such information itself. Nevertheless, there are some important differences in these models. Contrary to Bruce and Young, Damasio et al. believed that accessing contextual information in addition to activating the stored template is necessary to produce the experience of familiarity (Damasio et al. 1982, p. 340). In addition, Young and his associates were much more specific in their sugges- 
tions about the possible nature of face recognition units and the way in which they are connected to the rest of the face recognition system. Hence, it is their model that we used to provide the theoretical basis for the present study.

According to Bruce and Young (1986), a face recognition unit is in many ways analogous to Morton's (1969) notion of a "logogen" in word recognition. Indeed, it has recently emerged that many of the findings that provide the strongest support for a logogen system, such as perceptual facilitation due to priming, can be observed with faces as well as with words. Bruce and Valentine (1985) showed that a familiarity decision to a famous face is significantly speeded up if subjects were recently exposed to a picture of the same face. This occurs even if the two pictures are different (e.g., taken from a different angle). In a subsequent study, Bruce and Valentine (1986) showed that such familiarity decisions on famous faces were facilitated by over $100 \mathrm{msec}$ on average if they were presented immediately after a face with which they are strongly associated.

Decision latencies associated with the categorization of famous faces also have provided information concerning the different stages of face recognition postulated by Hay and Young (1982) and Bruce and Young (1986). Young, McWeeny, Hay, and Ellis (1986) showed that familiarity decisions can be made significantly more quickly than decisions about the occupations of famous faces. This is consistent with the suggestion that contextual information is accessed at a stage subsequent to activation of face recognition units. This view also was supported in a further experiment (Young, McWeeny, Hay, \& Ellis, 1986), which showed that taking the famous faces from a single category (politicians) reduced occupation judgment reaction times without having any effect on familiarity decisions.

In a subsequent study, Young, McWeeny, Ellis, and Hay (1986) showed that naming a famous face took significantly longer than making a familiarity decision or a decision about occupation. This was in marked contrast to written names of famous people, which took longer to categorize as familiar and to make occupation decisions about than to name. This supports the view that naming a face occurs at a stage subsequent to both the activation of face recognition units and the accessing relevant contextual information. Faces, like objects (Warren \& Morton, 1982) but unlike written words (Schwartz, Saffran, \& Marin, 1980), appear to be linked to their names indirectly through the mediation of the contextual or semantic system.

Other evidence that relates to the model of Young and his colleagues comes from memory errors. It has already been mentioned that one can find a face familiar without recalling any contextual information about the person, and that one can retrieve contextual information from a familiar face without always remembering the person's name. In a diary study in which subjects were asked to keep a record of all occasions on which they had encoun- tered problems in recognizing people over a 7-week period, Young, Hay, and Ellis (1985) found ample examples of people describing experiences such as these. However, they found no incidents reported in which subjects had been able to name a person while simultaneously being unable to remember anything else about the person or without finding the face familiar. Although one would not expect these types of errors on the basis of their model, there seems no reason in principle why someone could not name a face without knowing, say, what the person does or where he/she has been encountered previously. The absence of such errors appears, therefore, to provide strong support for Young and his colleagues' model of face recognition.

The present study investigated the types of memory errors that subjects make in face recognition, but in a laboratory situation in which subjects were presented with photographs of faces of famous people and were asked to provide different types of information about them. This information included whether or not the face was familiar, what the person's occupation was, and what he/she was called. It was hypothesized on the basis of the model that subjects would know a celebrity's occupation only when they also found the face familiar. More interestingly, the model also predicted that subjects would not be able to recall the name of a face unless they also knew the celebrity's occupation.

Of major importance, Experiment 1 included another manipulation in which subjects were provided with a cue so that we could investigate whether this would help them to retrieve names that they were initially unable to recall. One-third of the subjects received a second photograph of the celebrity as a cue, one-third received extensive biographical information about the celebrity, and one-third received four sets of initials, one of which was those of the appropriate celebrity. All trials on which subjects originally had been unable to name the face correctly were categorized into three types: face found unfamiliar; face found familiar, but occupation and name unknown; face found familiar and occupation known, but name unknown. We then noted how often the subject was able to provide the names to cues for faces categorized into each of the types. We hypothesized that a second photograph would be most useful when a face had previously been categorized as unfamiliar since it might help the subject activate the appropriate recognition unit in memory. This presumably would have already occurred if the face had originally been found familiar, so the photograph should be of less value. We also hypothesized that biographical or contextual information would be least likely to elicit the celebrity's name when the subjects already knew the occupation of the person. Conversely, this type of information might prove extremely useful to subjects who found the face familiar but did not know the occupation, since it would help them through the stage at which the system was encountering difficulties. Similarly, we hypothesized that the initials might prove particularly helpful when the subjects found the face familiar and knew 
the person's occupation, since such a cue might help to bridge the gap between the semantic/contextual system and the celebrity's name in the lexical system.

Therefore, the present study bears some resemblance to Yarmey's (1973) "tip-of-the-tongue" investigation of the information that subjects had available when they found a famous face familiar but were, initially at least, unable to produce the name. It extends Yarmey's study in that, on the basis of Bruce and Young's (1986) model, it explicitly distinguishes familiarity alone from a feeling of familiarity plus ability to provide contextual information, and compares both with an initial state of unfamiliarity. It also differs from Yarmey's study in that it provides subjects with cues to help them retrieve the name rather than asking them to produce whatever information about the person they can. As such, the design perhaps owes as much to the "feeling-of-knowing" experiments of Hart (1965) and others as it does to the typical tip-of-the-tongue design derived from the work of Brown and McNeill (1966).

\section{EXPERIMENT 1}

\section{Method}

Subjects. Sixty students from Newcastle Polytechnic volunteered to take part in the experiment and were tested individually. Twenty subjects were randomly allocated to each of the three subject groups. Three subjects, one from each condition, were dropped from the analysis and were replaced by 3 new subjects from the same population. This was because 2 of the subjects named so many of the celebrities that they produced insufficient usable data. Indeed, one of them successfully named every famous face. Conversely, the 3rd subject was dropped because she claimed not to find any of the faces familiar.

Stimuli. Two different photographs of each of the faces of 48 famous people and 48 photographs of people who are not famous were collected from newspaper and magazines. Each photograph was cut around the hairline to remove background context and was presented to subjects on a $10 \times 15 \mathrm{~cm}$ white card. Twelve celebrities were drawn from each of four different occupations: actors/ actresses, politicians, pop stars, and sportsmen/women. More information about the celebrities is presented in the Appendix.

Design and Procedure. The 96 cards were presented to the subjects in a random order one at a time. As each card was presented, the subjects were asked whether the face was familiar to them. They were told to answer either "familiar" or "unfamiliar." On trials on which the photograph was not of a famous person, the subjects were told that this was the case after they had made the familiarity decision, and the next photograph was then shown. There was no time limit imposed on any response in the experiment. On trials on which a famous face was shown, the subjects were then asked to give the occupation of the person. Throughout the experiment, they had in front of them a card that had printed on it the four occupations from which the celebrities were drawn. The subjects were told to select one of these and to indicate whether this was a guess or whether they knew the occupation; those who got the occupation correct as a result of a guess were not considered to "know" the occupation. The subjects were then asked to give the name of the celebrity.

Following this, the subjects were given one of three types of cue depending on to which group they had been assigned. The subjects in the photograph group were presented with a second photograph of the celebrity in question and were again asked to provide the name. The subjects in the initials group were presented with a card on which was printed the initials of four famous people. The subjects were told that one of these sets of initials was those of the celebrity in question and were again asked to provide the celebrity's name. In addition to the initials, there was a dash to indicate how many letters there were in each of the celebrities' names. For example, the Orson Welles card was as follows:

$$
\begin{aligned}
& \text { (i) } \mathrm{J} \ldots \mathrm{H} \ldots \mathrm{H}-\ldots \\
& \text { (ii) } \mathrm{O} \ldots-.- \\
& \text { (iii) } \mathrm{D}-\ldots \mathrm{N}-\ldots \\
& \text { (iv) } \mathrm{A} \ldots \ldots
\end{aligned}
$$

The subjects in the context group were given a card that provided fairly extensive biographical detail about the celebrity and were once more asked if they could produce the person's name. For Michael Heseltine the card read, "He is nicknamed Tarzan, darling of the Tory Party due to his leonine good looks. He recently caused turmoil in the cabinet by resigning from his defense post in sensational style and publicly criticized the Prime Minister." The card for Seve Ballesteros read, "Brilliant cavalier Spanish golfer whose raw ability and adventurous play have carried him to the top of his sport."

Finally, the subjects were given four names on another card and were asked to select the correct name. Once more they were asked whether they knew the answer or whether it was a guess. The other three names on the card were selected from the same occupation as the celebrity and, as far as possible, were chosen so that they had something in common with the celebrity in question. For Michael Heseltine, for instance, the distractors were Cecil Parkinson, John Nott, and Lord Carrington, all of whom have departed from senior posts in Prime Minister Thatcher's cabinet in relatively controversial fashion. The three distractors were the same names as those presented earlier in fragmented form to the subjects in the initials group as cues for the recall of the name. For the Orson Welles example, the other names were John Huston, David Niven, and Alfred Hitchcock.

\section{Results and Discussion}

Cued recall of names. The effect of cues on subjects' abilities to retrieve names that they had originally been unable to recall is summarized in Table 1 . These data were subjected to a $3 \times 3$ analysis of variance (ANOVA) in which the factors were type of cue and initial state of knowledge. Such an analysis was considered appropriate, although it must be acknowledged that initial state of knowledge is not strictly speaking a true independent variable. The analysis revealed a significant main effect for cue type $[F(2,57)=5.58, M S e=.072, p<.01]$ and for initial state of knowledge $[F(2,114)=4.84, M S e=$ $.032, p<.01]$. Of major interest, there was a highly significant interaction between these two factors $[F(4,114)$ $=9.46, \mathrm{MSe}=.032, p<.001]$.

This significant interaction was further investigated by separate one-way ANOVAs on the data from each of the

\begin{tabular}{|c|c|c|c|}
\hline \multirow[b]{2}{*}{ Cue Type } & \multicolumn{3}{|c|}{ Initial State of Knowledge } \\
\hline & Unfamiliar & $\begin{array}{l}\text { Familiar } \\
\text { Only }\end{array}$ & $\begin{array}{l}\text { Familiar and } \\
\text { Occupation } \\
\text { Known }\end{array}$ \\
\hline Photograph & .29 & .30 & .31 \\
\hline Context & .41 & .52 & .35 \\
\hline Initials & .12 & .22 & .47 \\
\hline
\end{tabular}

Table 1

Proportion of Names Successfully Retrieved in Cued Recall as a Function of Cue Type and Initial State of Knowledge in Experiment 1 
three subject groups. This revealed that there were no differences in recall for subjects in the photo group $(F<1)$. There were significant effects, however, in both the context group $[F(2,38)=6.20, M S e=.024$, $p<.01]$ and the initials group $[F(2,38)=22.27, M S e=$ $.028, p<.001]$. Newman-Keuls post-tests revealed that in the context group the cue proved more successful when subjects initially had found the face to be familiar but did not know the occupation than when subjects had at first found the face unfamiliar $(p<.05)$ or when they had found the face familiar and knew the occupation $(p<.01)$. The other comparison did not reach significance. In the initials group, Newman-Keuls post-tests showed that the cue was more effective when subjects had at first found the face familiar and knew the occupation than when they had found the face unfamiliar $(p<.01)$ or when they had found the face familiar but did not know the occupation $(p<.01)$. The other comparison just failed to reach significance $(p>.05)$.

The cued recall data was also analyzed conditionalized on successful recognition. This was done because it is always possible that a subject fails to recall a name on a particular occasion not because of any retrieval failure per se, but because the name of the celebrity is not stored in the subjects' memory. If performance is conditionalized on subsequent successful recognition, then it seems reasonable to assume that virtually all failures to recall the name should be genuine retrieval failures. The relevant means for this analysis are presented in Table 2 . A two-way ANOVA revealed a significant main effect for subject groups $[F(2,57)=5.28, M S e=.084, p<.05]$, no effect for cue type $(F<1)$, and a significant interaction between these factors $[F(4,114)=7.60, M S e=$ $.063, p<.001]$. Once more, the significant interaction was further investigated by separate one-way ANOVAs for each of the three subject groups. This revealed no significant differences in the photo group $[F(2,38)=1.50$, $M S e=.070, p>.05]$. There were, however, significant effects in both the context group $[F(2,38)=7.43$, $M S e=.048, p<.01]$ and the name group $[F(2,38)=$ $7.13, M S e=.071, p<.01]$. Newman-Keuls post-tests revealed that in the context group the cue proved more successful when the face was initially found unfamiliar than when the occupation was known $(p<.05)$ and more successful when the face was initially familiar but the occupation was not known than when the occupation was known $(p<.01)$. Post-tests showed in the initials group that recall was better when occupation was known than when the face was found unfamiliar $(p<.01)$ or when the face was familiar but the occupation was not known $(p<.01)$.

In many respects, these results fit well with the predictions derived from Bruce and Young's (1986) model of face recognition. The effectiveness of the follow-up cues was strongly influenced by the initial state of knowledge that the subject was experiencing. Particularly striking is the finding that contextual information about a person was significantly less useful as a cue when subjects had ini- tially found the face familiar and also knew the occupation than when they had found the face familiar only. Indeed, subjects were slightly less likely to produce the name in response to a contextual cue when they knew a celebrity's occupation than they were when they did not initially find the face familiar at all. When performance was conditionalized on successful subsequent recognition (see Table 2), this difference reached statistical significance. Such results, which might otherwise appear paradoxical, support the view that successive, distinct stages are involved in face identification. When subjects know the occupation associated with a face, then extra information relating to that domain of knowledge is of relatively little value to them even if, as in the present situation, the extra contextual information is quite detailed. Subjects already have access to the information they know about the person that is stored at this level. What they need is some cue that will help them to progress to the next level, the lexical domain in which the names are stored.

The completely different pattern of results obtained when initials were used as cues can also be explained by Bruce and Young's (1986) model. The initials cues were particularly helpful when subjects already knew the occupation of the celebrity but not the name, because it helped them bridge the gap between contextual information in the person-specific semantic system and the name in the lexical output system. The initials cues were less useful when subjects were in a familiar-only or an unfamiliar state, because on these occassions subjects were unlikely to have reached the semantic domain and were therefore less able to take advantage of a link from the semantic system to the lexical system.

In other respects, however, the cued recall results did not turn out exactly as anticipated. It was predicted from the model of Bruce and Young (1986) that a second photograph might enable a subject to progress from an initial state of unfamiliarity to successful activation of the face recognition unit. If, as one would assume, this was the stage at which the system was encountering difficulties, then the photograph cue should prove relatively useful. However, the results showed that the photograph cue was no more helpful than when the face had initially been found familiar, or when the face was found familiar and the occupation was known. This was surprising since it had been anticipated that when subjects were in the other two states, the photograph cue would not provide them

Table 2

Proportion of Names Successfully Retrieved in Cued Recall when Scores are Conditionalized on Successful Subsequent Recognition of the Name in Experiment 1

Initial State of Knowledge

\begin{tabular}{lccc} 
& \multicolumn{3}{c}{ Initial State of Knowledge } \\
\cline { 2 - 4 } Cue Type & Unfamiliar & $\begin{array}{c}\text { Familiar } \\
\text { Only }\end{array}$ & $\begin{array}{c}\text { Familiar and } \\
\text { Occupation } \\
\text { Known }\end{array}$ \\
\hline Photograph & .54 & .50 & .40 \\
Context & .63 & .72 & .45 \\
Initials & .34 & .34 & .62 \\
\hline
\end{tabular}


with any information that they did not have available already. We considered it possible that subjects might have had fewer of the names of faces that they had found unfamiliar stored in memory, and that this might have obscured any advantages associated with photograph cues when subjects found faces unfamiliar. Recall performance conditionalized on subsequent successful recognition of the names was therefore examined to see whether any differences might emerge on trials where subjects would appear highly likely to have the name stored in memory. Although it can be seen from Table 2 that descriptively differences did start to appear in the predicted direction, the analysis failed to reveal any statistically significant effects. One problem with this analysis, however, was the fact that it was performed on a relatively small amount of data, which may have rendered it somewhat insensitive.

There is, however, another possible reason why results with the photograph cue did not appear to fit the model of Bruce and Young (1986). ${ }^{1}$ It may be that on some occasions the extra retrieval time that the subject received when given a cue might itself have been enough to allow the name to be recalled. Simply trying once more to retrieve the name might sometimes have been all that was required for name retrieval. ${ }^{2}$ If it is true that the new cue was sometimes superfluous, then a control condition in which subjects were allowed a second opportunity for recall without any additional cues might help to clarify the situation. If it is only when a face is initially deemed unfamiliar that subjects given a new photograph do better than subjects simply given a second opportunity to recall the name from the same photograph, then the Bruce and Young model would be vindicated after all. Such a possibility is investigated in Experiment 2.

Recognition memory for names. Subjects' abilities to recognize subsequently the name of the celebrities is summarized in Table 3, as a function of initial state of knowledge and cue type. A two-way ANOVA revealed a significant main effect for initial state of knowledge $[F(2,114)=34.45, M S e=.034, p<.001]$ and for cue type $[F(2,57)=3.83, M S e=.085, p<.05]$. The interaction between these factors was also significant $[F(4,114)=3.29, M S e=.034, p<.05]$. The significant interaction was further investigated by separate oneway analyses on the data from each of the three subject groups. These revealed significant main effects in each

Table 3

Proportion of Names Successfully Recognized as a Function of Cue Type and Initial State of Knowledge in Experiment 1

Initial State of Knowledge

\begin{tabular}{|c|c|c|c|}
\hline Cue Type & Unfamiliar & $\begin{array}{c}\text { Familiar } \\
\text { Only }\end{array}$ & $\begin{array}{c}\text { Familiar and } \\
\text { Occupation } \\
\text { Known }\end{array}$ \\
\hline Photograph & $.50 \quad(.74)$ & $.56 \quad(.79)$ & $.76 \quad(.90)$ \\
\hline Context & $.60(.76)$ & $.74 \quad(.82)$ & $.76 \quad(.88)$ \\
\hline Initials & $.34 \quad(.59)$ & $.57 \quad(.79)$ & $.76 \quad(.90)$ \\
\hline
\end{tabular}

Note-Figures in parentheses include trials on which subjects indicated that they guessed the correct name. of the three groups: for the photograph cue $[F(2,38)=$ $8.06, M S e=.046, p<.01]$, the context cue $[F(2,38)$ $=8.10, M S e=.019, p<.011$, and the name cue $[F(2,38)=23.47, \mathrm{MSe}=.037, p<.0011$. A very similar pattern was revealed when the analysis was performed on data that included trials in which subjects had recognized the name correctly as a result of a guess (the figures in brackets in Table 3).

These results show that subjects were able to recognize many names they had previously failed to recall. This suggests that many names were available in memory even though they were not accessible from the recall cues provided. It is also interesting to note that in the recognition test for the names, faces for which the occupation could originally be given were consistently associated with performance as good as, if not better than, faces found unfamiliar or familiar only. This makes the relatively poor cued recall of names that was sometimes observed when the occupation was known all the more striking.

Overall levels of face recognition. The overall proportion of famous faces judged familiar by subjects when they saw them originally was .63 , compared with .13 of nonfamous faces. This difference was highly significant $[F(1,57)=723.92, M S e=.002, p<.001]$. Rather less predictable was the finding that there was a significant difference between the three groups of subjects in terms of which group found the most faces familiar $[F(2,57)=$ $3.51, M S e=.003, p<.05]$. Newman-Keuls post-tests revealed that this was caused by subjects in the photo group (.34) finding fewer of the faces familiar overall than subjects in the initials group (.46). Neither group differed significantly from the context group (.39). There were no differences between the subject groups in terms of number of occupations that were known before the cues were given $[F(2,57)=2.03, M S e=.004, p>.05]$ or in the number of correct names produced without cues $(F<1)$. Altogether, the proportion of photographs of celebrities for which the occupation was known originally was .49 , and the proportion of faces named immediately was .33 .

This pattern of performance suggests that a criterion difference may have been operating, with subjects in the photograph condition being more reluctant to call a face familiar. The criterion difference can be observed clearly in Table 4, which summarizes the number of different types of responses made by subjects in the three groups when the photographs were originally shown prior to presentation of the cues. ${ }^{3}$ The error data were subjected to a 3 (unfamiliar, familiar, occupation) $\times 3$ (context, photograph, initials) ANOVA to discover whether the different types of error occurred with equal frequency in the different groups. This analysis revealed a significant effect for type of error $[F(2,114)=123.09, M S e=.002$, $p<.001]$, no effect for subject group $(F<1)$, and a significant interaction between these two factors $[F(4,114)$ $=3.69, M S e=.002, p<.01]$. Newman-Keuls posttests revealed that in all three groups most errors fell into the unfamiliar category, with the other two error types not differing significantly in any of the three groups. 
Table 4

Proportion of Faces Found Unfamiliar, Familiar Only, Familiar and Occupation Known, and Named in Each of the Three Subject Groups in Experiment 1 Prior to Presentation of the Retrieval Cues

\begin{tabular}{lcccc}
\hline & \multicolumn{4}{c}{ Original Knowledge of Faces } \\
\cline { 2 - 5 } Cue Type & Unfamiliar & $\begin{array}{c}\text { Familiar } \\
\text { Only }\end{array}$ & $\begin{array}{c}\text { Familiar and } \\
\text { Occupation } \\
\text { Known }\end{array}$ & Named \\
\hline Photograph & .43 & .13 & .14 & .30 \\
Context & .37 & .13 & .16 & .34 \\
Initials & .33 & .15 & .19 & .33 \\
Overall & .37 & .13 & .16 & .33 \\
\hline
\end{tabular}

Therefore, the interaction appears to reflect the greater difference between the error types of the photo group compared with those of the other two groups.

Relation between the original failures to name and Bruce and Young's (1986) model. The responses that subjects made prior to presentation of the cues were examined to see whether they conformed to a pattern consistent with Bruce and Young's (1986) model. This revealed that on $97.4 \%$ of trials where subjects knew the celebrity's name, they also knew the person's occupation and found the face familiar. On only one occasion (proportion $=.001$ ) was a name correctly given and the occupation known, without the face being found familiar. On 3 occasions (proportion $=.003$ ) a subject both failed to find the face familiar and did not know the occupation of the person but gave the correct name. On all 3 occasions, the subject concerned did guess the occupation correctly, and on 2 of the 3 occasions indicated that the name was a guess. On 20 occasions (proportion $=.021$ ) the face was found familiar and the right name was given but the occupation was unknown. On all 20 of these occasions, the subjects successfully guessed the correct occupation. There were four trials (proportion $=.002$ ) on which subjects who did not know the name knew the occupation without finding the face familiar.

Therefore, the nature of the errors that subjects made prior to presentation of the cues revealed a pattern that was consistent with the findings of Young et al. (1985) and the model of Bruce and Young (1986). On by far the majority (.97) of trials on which subjects gave the correct name, they also found the face familiar and knew the occupation. Similarly, on $99.8 \%$ of trials on which the name of the face was not given but the occupation was known, the face had previously been found familiar. Conversely, on a comparatively large proportion of trials on which a face was found familiar, the occupation was not known (.22). Similarly, on a relatively large proportion of the trials where the occupation was known, the face was not named (.34). This pattern further supports the view that before a face can be named, contextual information relating to the person must be accessed in memory and, before this can happen, an appropriate face recognition unit must be activated.

It must be pointed out, however, that the above pattern was not quite as clear-cut as that in the diary study reported by Young et al. (1985), in which no faces were named without contextual information being accessed and the face was always found familiar if contextual information was retrieved. The overwhelming majority of the deviations in the present study are probably due to the design used. For instance, on the $\mathbf{2 3}$ occasions in which subjects gave the name but did not know the celebrity's occupation, they always successfully managed to guess the occupation. It may well have been the case, therefore, that these subjects had indeed accessed contextual information about the person concerned prior to producing the name, even though they claimed not to know the celebrity's occupation. On the 4 occasions on which the face was named without being found familiar, the occupaton was known or guessed correctly after the face had been judged unfamiliar, before the name was given. It may have been the case that encouraging the subject to think about the occupation did activate the face recognition unit and make the face seem familiar to the subject after the initial familiarity decision had been made. It would have been interesting to have investigated this by asking those subjects who, for instance, named the face after previously only guessing its occupation or those who named the face after initially finding it unfamiliar, whether they now felt differently about occupation and familiarity. We believe that it may be the absence of such a stage in the present experiment that has made the results slightly different from those reported by Young et al. (1985). Such a possibility was investigated in Experiment 2.

Subjects' abilities to "guess" the correct occupation. There is one remaining aspect of the results that is relevant to Bruce and Young's (1986) model. They suggested that decisions about, say, a person's occupation might be made not via the appropriate face recognition unit and the identity-specific contextual/semantic system, but instead by what they refer to as a "visually derived semantic code." Certain physical characteristics of a face, such as age or hairstyle, are likely to influence one's decision as to whether an individual is, say, a pop star or a politician. Visually derived semantic codes should, therefore, mean that it is sometimes possible to make reasonably accurate decisions about a person's occupation even though one has not accessed any information in memory that is specific to that individual. The present study provides support for this viewpoint since subjects were able to "guess" the occupations of celebrities that they claimed not to know with a probability of .52 (chance $=.25$ ). Ability to guess the occupation was not affected by subject group $[F(2,57)$ $=1.44, M S e=.043, p>.05]$.

\section{EXPERIMENT 2}

Taken together, the results of Experiment 1 provided many findings that can be explained in terms of Bruce and Young's (1986) model of face recognition. The main exception was the pattern of results obtained when a second photograph was used as a retrieval cue: no differences were observed as a function of subjects' initial state 
of knowledge, even though it was expected that a new photograph would most benefit subjects who had found the original photo unfamiliar. We therefore decided to conduct an additional experiment to investigate further the effects of photograph cues. Several modifications were made to the design of the previous experiment. First, the number of trials was increased from 96 to 160 . This was done to investigate the possibility that the lack of any differences in the photograph-cue condition in Experiment 1 came about because an insufficient number of photographs were used. Second, to reduce the likelihood of the criterion difference that seemed to occur in Experiment 1, a two-phase procedure was adopted in which subjects received only the second photograph of those celebrities they had failed to name after they had been through all the photographs once. Finally, and most important, the performance of these subjects was compared with that of control subjects, who in Phase 2 were presented with the same photographs of the celebrities they had failed to name in Phase 1 . This was done to investigate whether an additional opportunity to recall the name might sometimes be the crucial factor in eliciting the desired response rather than the additional information provided by a new photograph. Should this turn out to be the case, then it would be predicted from Bruce and Young's (1986) model that a different photograph would be more beneficial than the same photograph when the subject originally found the face unfamiliar, but not when the subject had found the face familiar already or had found the face familiar and knew the occupation already. Bruce and Young's model therefore predicts an interaction between the type of photograph and the subjects' initial state of knowledge.

\section{Method}

Subjects. Thirty-four staff and students from Newcastle Polytechnic volunteered to take part in the experiment and were tested individually. Seventeen subjects were randomly allocated to the same-photo condition and 17 were allocated to the different-photo condition. One subject had to be dropped for producing insufficient usable data, having known the occupations of every face she found familiar, and was replaced by another subject from the same population.

Stimuli. The photographs used in the study were different from those used in Experiment 1. They were all $31 / 2 \times 5$ in. black-andwhite photographs. Pictures of celebrities and people who were not famous were presented in the same standardized format. A total of 160 people were used, 80 of whom were celebrities. The celebrities comprised 20 actors/actresses, 20 politicians, 20 sportsmen/women, and 20 singers. Details about the celebrities are given in the Appendix.

Design and Procedure. The design and procedure were similar to those used in Experiment 1, but included the following changes: First, only two groups of subjects were used; one group received a different photograph of those celebrities whom they were initially unable to name, whereas the other group received the initially viewed photograph once more. Second, all subjects went through all the photographs once and received the second photograph (or the initial photograph once again) of only those celebrities they could not name in a subsequent second phase of the experiment that began a few moments after the first phase was completed. (In Experiment 1 , the subjects had received a cue immediately after they had failed to name a celebrity.) As in Experiment 1, the subjects were asked if they knew the occupation and name of the celebrity following the familiarity judgment. Occasionally, the subjects knew the occupation of the person, having previously failed to find the face familiar, and on some of these trials even went on to successfully name the face. Unlike in Experiment 1, when this occurred, the subjects were asked if they now found the face familiar. Finally, the subjects were given the recognition test only if they failed to identify the celebrity in either Phase 1 or Phase 2 of the experiment.

\section{Results and Discussion}

Cued recall of names. The effect of the photograph cues on subjects' abilities to retrieve the names of celebrities they had failed to identify in Phase 1 is summarized in Table 5. A two-way ANOVA showed a significant main effect for type of photo $[F(1,32)=6.13, M S e=$ $.051, p<.05]$ and no main effect for initial state of knowledge $[F(2,64)=2.03, M S e=.035, p>.05]$. Of most interest was the significant interaction between these factors $[F(2,64)=4.08, M S e=.035, p<.025]$. The interaction was further investigated by tests for simple main effects. These revealed that subjects who received a different photograph as a cue performed significantly better than subjects who received the same photograph when in an initial state of unfamiliarity $[F(1,93)=9.60$, $M S \mathrm{e}=.040, p<.01]$ and an initial state of familiarity only $[F(1,93)=5.00, M S e=.040, p<.05]$. There was no difference between the two groups when they had been in a state of familiarity and also knew the celebrity's occupation $(F<1)$.

Table 6 reveals the results conditionalized on subsequent recognition of the celebrity's name. It can be seen that descriptively Table 6 reveals a similiar pattern to that of Table 5, and there was once more a significant main effect for type of photograph $[F(1,32)=7.17, M S e=$ $.060, p<.025]$ and no effect for initial state of knowledge $[F(2,64)=1.01, M S \mathrm{e}=.049, p>.05]$.

Table 5

Proportion of Names Successfully Retrieved in Cued Recall as a Function of Type of Photograph and Initial State of Knowledge in Experiment 2

\begin{tabular}{lccc}
\hline & \multicolumn{2}{c}{ Initial State of Knowledge } \\
\cline { 2 - 4 } Type of Photograph & Unfamiliar & $\begin{array}{c}\text { Familiar } \\
\text { Only }\end{array}$ & $\begin{array}{c}\text { Familiar and } \\
\text { Occupation } \\
\text { Known }\end{array}$ \\
\hline Same & .08 & .13 & .29 \\
Different & .30 & .28 & .26 \\
\hline
\end{tabular}

Table 6

Proportion of Names Successfully Retrieved in Cued Recall When Scores are Conditionalized on Successful Subsequent Recognition of the Name in Experiment 2

\begin{tabular}{lccc}
\hline & \multicolumn{3}{c}{ Initial State of Knowledge } \\
\cline { 2 - 4 } Type of Photograph & Unfamiliar & $\begin{array}{c}\text { Familiar } \\
\text { Only }\end{array}$ & $\begin{array}{c}\text { Familiar and } \\
\text { Occupation } \\
\text { Known }\end{array}$ \\
\hline Same & .11 & .17 & .30 \\
Different & .36 & .31 & .30 \\
\hline
\end{tabular}


This time, however, the interaction just failed to reach significance $[F(2,64)=2.75, M S e=.049, p=.07]$.

These findings have clarified considerably the results of Experiment 1. It can be seen from Table 5 that the pattern of performance with different photographs in Experiment 2 is quite similar in character to that obtained in Experiment 1 . However, the performance by the subjects in the same-photo condition makes it clear that a different photograph helps subjects when they find the original photograph unfamiliar or familiar only, but not when they find the original photo familiar and also know the occupation. The ability of subjects to retrieve the name when they find the face familiar and also know the occupation can consequently be attributed to the extra opportunity for retrieval itself rather than to the new information provided by a different photograph.

It is interesting that subjects can so frequently retrieve the person's name when in this state of knowledge if given a further opportunity. A second opportunity even with the same photo seems to help somewhat in the other states of knowledge also. Of major interest, however, is that the results with photograph cues are now much closer to what one would expect from Bruce and Young's (1986) model than appeared to be the case following Experiment 1. A different photograph helps one retrieve a celebrity's name when one did not originally find the face familiar but is of no help when one has already accessed semantic information about the person. A different photograph could be expected to increase the chance that the appropriate face recognition unit would be activated; thus, it will help subjects who find the original face unfamiliar, but will be of no help to subjects who require some bridge from the semantic system to the lexical output system, and so is of no value if one already knows the occupation. New photographs are no better than the original photographs when one is in such a state.

It must be acknowledged, however, that performance when subjects at first find the face familiar but do not know the occupation is not what would be expected on the basis of Bruce and Young's (1986) model. Subjects in this state found it significantly easier to name the celebrity in Phase 2 from a different photograph than from the same photograph. This was not anticipated, because although a new photograph would be expected to sometimes allow a previously nonactivated face recognition unit to fire, the recognition unit should already have fired if the face had previously been judged familiar. It is therefore surprising that new photos led to more names being retrieved than old photos when subjects were in this state.

Because of the unexpected nature of this result, subjects in the different-photo condition were subsequently questioned informally as to why a new photo was so beneficial when they already had found the face familiar in the previous phase of the experiment. Subjects more than once replied that although they had not recognized a face overall, they had sometimes responded "familiar" because they had recognized a particularly distinctive feature of the face, such as the shape of the person's eyes or the lips when he/she smiled. We therefore believe it is possible that when a subject reports a feeling of familiarity, it does not necessarily mean that the face recognition unit itself has fired. Since person-specific semantic information and, hence, the appropriate name still could not be accessed unless the face recognition unit fired, then a new photo would be more beneficial than the old photo if it contained enough new information to activate the face recognition unit, whereas the old photo had led to a feeling of familiarity via recognition of an individual feature. The question of whether a familiarity decision is occasionally made on the basis of partial recognition of a face is therefore an interesting issue for future research to consider.

Overall levels of face recognition. The overall proportions of famous faces judged familiar were .85 in the same-photo condition and .86 in the different-photo condition. These were significantly higher than the proportions of nonfamous faces judged familiar $[F(1,32)=$ $959.82, \mathrm{MSe}=.006, p<.001]$, which were .12 in the same-photo condition and .11 in the different-photo condition. There was no difference between the two groups and no interaction between type of group and type of photo (both $F s<1$ ). The proportion of occupations known by subjects in Phase 1 was .78, and the proportion of names correctly recalled in Phase 1 was .62. In neither case were there any significant differences between the two groups $(F<1)$.

Whereas $15 \%$ of the famous faces were deemed unfamiliar in Phase 1,7\% were deemed familiar without the occupation being known, and $16 \%$ were found familiar with the occupation but not the name being known. There was a significant difference between these figures $[F(2,64)$ $=13.55, M S e=.004, p<.001]$. Newman-Keuls tests showed that this arose because significantly fewer errors of the face-found-familiar-only type were made than errors of the other two kinds (both comparisons, $p<.01$ ). Number of errors did not differ significantly in the two subject groups $(F<1)$, and the interaction between type of error and subject group also was not significant $(F<1)$.

It is clear from these results that the criterion differences observed in Experiment 1 were not observed in the present study. In Phase 1, subjects in both groups judged equivalent numbers of faces to be familiar and knew equivalent numbers of occupations and names. The three different types of failures to name faces also occurred equally frequently in the two subject groups.

Relation between failures to name in Phase 1 and Bruce and Young's (1986) model. In Experiment 2, there were no trials on which subjects named a face without knowing the person's occupation and no trials on which subjects knew the occupation without finding the face familiar. There were a few occasions on which subjects said they knew the occupation after previously saying that the face was unfamiliar (such a situation was sometimes observed in Experiment 1). Upon questioning, however, subjects who stated that they knew the occupation always accepted that they actually found the face familiar. This 
slight change in procedure, as well as the absence of any trials in which the subject knew a celebrity's name but not his/her occupation, means that the results are now much closer to those obtained by Young et al. (1985) and those predicted by Bruce and Young (1986).

Subjects' abilities to "guess" the correct occupation. In Experiment 1, subjects were able to guess the occupations of celebrities whose faces they found unfamiliar or familiar with a probability of only .52 (chance $=.25$ ). A very similar pattern emerged in Experiment 2 with subjects correctly guessing .50 (chance $=.25$ ) of the occupations. There was no significant difference between the two groups of subjects in terms of the number of correct guesses made.

These findings are once more consistent with Bruce and Young's (1986) suggestion that one can sometimes make reasonably accurate decisions about a person's occupation on the basis of a visually derived semantic code. According to Bruce and Young, this does not require that one access any information in memory that is specific to that individual. If it is true that these decisions are made independent of any person-specific information, then they should be equally accurate regardless of whether the name of the person is subsequently recalled or recognized. This indeed turned out to be the case. Where the name was eventually remembered in Phase 2, .49 of occupation guesses were correct. Where the name was neither recalled nor recognized in Phase 2, .51 of occupation guesses were correct. This difference was not significant.

\section{GENERAL DISCUSSION}

The results of the two experiments support Bruce and Young's (1986) model of face recognition in three main ways. First, they were consistent with the view that subjects can make reasonably accurate decisions about people's occupations on the basis of visually derived semantic codes that do not require that one access any person-specific semantic information. Second, they were consistent with the diary study of Young et al. (1985), in that the failures to name people fell into certain categories rather than others. Most interestingly, although one can often remember someone's occupation but not his/her name, situations in which one can remember someone's name but not his/her occupation (or some other fact about the person) appear to occur extremely rarely, if at all. The very different conditions under which the present experiments and Young et al.'s (1985) study were carried out suggests that this finding is indeed a robust one.

Third, and most important, the present study shows that the three states of partial knowledge that Bruce and Young (1986) identify - unfamiliarity, familiarity, and familiarity and contextual information available - can be functionally distinguished in terms of the differential probability that a face can be named in response to three distinct types of cue. Experiment 1 revealed that biographical information is of most value when one finds a face familiar only and of least value when one already knows the per- son's occupation. Conversely, a name cue was most valuable when one already knew the person's occupation. Experiment 2 made it clear that a second photograph is more beneficial when one has found a face unfamiliar than when one already knows the person's occupation. These findings are consistent with the view that a second photograph may activate a face recognition unit that has not fired previously, that contextual information may enable the subject to access precise person-specific information in the semantic system, and that the initials cues may enable one to bridge the gap between the semantic system and the name in the lexical output system. If a cue is to be maximally effective, it must assist the perceiver at the precise point in the system at which he/she is having difficulties. These results obtained with retrieval cues join the growing body of evidence observed in reaction time studies and studies of priming (Bruce \& Valentince, 1985, 1986; Young, McWeeny, Ellis, \& Hay, 1986; Young, McWeeny, Hay, \& Ellis, 1986), studies of episodic memory (Bruce, 1982; McWeeny, Young, Hay, \& Ellis, 1987), and neuropsychological case studies (De Haan, Young, \& Newcombe, 1987; Hanley, Young, \& Pearson, in press) that successive but distinct stages are involved in face identification.

One final question can be discussed in relation to the present study, namely the issue of whether there are special mechanisms for processing faces. The recent reaction time study of Young, McWeeny, Ellis, and Hay (1986) emphasized similarities between the cognitive processes involved in recognizing faces and those involved in recognizing objects. A similar conclusion can be drawn from the use of retrieval cues in the experiments reported earlier. Some of the problems encountered by normal subjects in recognizing faces in the present study have a clear parallel with the difficulties that aphasic patients encountered in their attempts to retrieve the names of common objects in the studies of Rochford and Williams (1962) and Hatfield, Howard, Barber, Jones, and Morton (1977). When these patients failed to name an object, then neither making the picture of the objects more realistic, nor placing the object in a more appropriate context, nor providing a description of the object's function proved particularly helpful. As Baddeley (1982, p. 723) pointed out in his discussion of these studies, such cues are ineffective because they merely "enhance a stage that is already functioning perfectly adequately."

The problems that the aphasics are encountering appear analogous to those faced by the subjects in the present study who found a face familiar and knew the occupation but could not retrieve the name. In both cases, extra contextual information proved to be of limited value. Interestingly, both the subjects in this condition in the present study and the aphasics observed by Rochford and Williams (1962) were helped considerably more by cues that were associated with the names of the people or objects themselves: initials in the present study and rhymes and spellings in Rochford and Williams's study. It would be interesting to use retrieval cues in future studies to ob- 
serve whether the other types of difficulty that subjects encountered in recognizing faces in the present study might also have a counterpart in the problems suffered by other anomic or agnosic patients.

\section{REFERENCES}

Baddeley, A. D. (1982). Domains of recollection. Psychological Review, 89, 708-729.

Brown, R., \& MCNeILl, D. (1966). The "tip of the tongue" phenomenon. Joumal of Verbal Learning \& Verbal Behavior, 5, 325-337.

BruCE, V. (1982). Changing faces. Visual and non-visual coding process in face recognition. British Journal of Psychology, 73, $105-116$.

Bruce, V., VAlentine, T. (1985). Identity priming in the recognition of familiar faces. British Journal of Psychology, 76, 373-383.

Bruce, V., Valentine, T. (1986). Semantic priming of familiar faces. Quarterly Journal of Experimental Psychology, 38A, 125-150.

BRUCE, V., \& YounG, A. (1986). Understanding face recognition. British Journal of Psychology, 77, 305-327.

Damasio, A. R., Damasio, H., Van Hoesen, G. W. (1982). Prosopagnosia: Anatomical bases and behavioral mechanisms. $\mathrm{Neu}$ rology, 32, 331-341.

De Hann, E. H. F., Young, A. W., Newcombe, F. (1987). Face recog nition without awareness. Cognitive Neuropsychology, 4, 385-415.

Hanley, J. R., Young, A. W., \& Pearson, N. A. (in press). Defective recognition of familiar people. Cognitive Neuropsychology.

HART, J. T. (1965). Memory and the feeling of knowing experience. Journal of Educational Psychology, 56, 208-216.

Hatfield, F. M., Howard, D., Barber, J., Jones, C., Morton, J. (1977). Object naming in aphasics: The lack of effect of context or realism. Neuropsychologia, 15, 717-727.

HAY, D. C., Young, A. W. (1982). The human face. In A. W. Ellis (Ed.), Normality and pathology in cognitive functions (pp. 173-202). London: Academic Press.

McWeeny, K. H., Young, A. W., Hay, D. C., Elus, A. W. (1987). Putting names to faces. British Journal of Psychology, 78, 143-149.

Morton, J. (1969). Interaction of information in word recognition. Psychological Review, 76, 165-178.

Rochford, G., \& Williams, M. (1962). Studies in the development and breakdown of the use of names: I. The relationship between nominal dysphasia and acquisition of vocabulary in childhood. Journal of Neurology, Neurosurgery \& Psychiatry, 25, 222-227.

Schwartz, M. F., SAfrran, E. M., Marin, O. S. M. (1980). Fractionating the reading process in dementia: Evidence for word specific print-to-sound associations. In M. Coltheart, K. Patterson, \& J. C. Marshall (Eds.), Deep dyslexia (pp. 259-269). London: Routledge \& Kegan Paul.

Tranel, D., Damasio, A. R. (1985). Knowledge without awareness: An autonomic index of facial recognition of prosopagnosics. Science, 228, 1453-1454.

WarRen, C., \& Morton, J. (1982). The effects of priming on picture recognition. British Journal of Psychology, 73, 117-129.

YARMEY, A. D. (1973). I recognize your face but I can't remember your name: Further evidence on the tip-of-the-tongue phenomenon. Memory \& Cognition, 1, 287-290.

YounG, A. W., HAY, D. C., \& EluIs, A. W. (1985). The faces that launched a thousand slips: Everyday difficulties and errors in recognizing people. British Journal of Psychology, 76, 495-523.

Young, A. W., McWeENY, K. H., Ellis, A. W., \& HAY, D. C. (1986). Naming and categorizing faces and written names. Quarterly Journal of Experimental Psychology, 38a, 297-318.

Young, A. W., McWeeny, K. H., HAY, D. C., \& Elus, A. W. (1986). Access to identity-specific semantic codes from familiar faces. Quarterly Journal of Experimental Psychology, 38A, 271-295.

\section{NOTES}

1. We are indebted to James Bartlett for offering this explanation of the results with the photograph cues and pointing out the need for Experiment 2.
2. Extra retrieval time may also have been the reason why subjects who received the context cues retrieved as much as $35 \%$ of the names when they already knew the celebrity's occupation. Conversely, subjects receiving context cues may have retrieved $41 \%$ of the names when they originally found the face unfamiliar because they could identify the person from the semantic information despite failing to recognize the photograph.

3. The most important experimental manipulation (the effect of cues on recall of names) clearly depended on subjects' producing sufficient numbers of the three types of error if meaningful comparisons were to be made. The 3 subjects who were dropped from the analysis did not provide a single example of one of the three types of error. Of the subjects that remained, on only one occasion did a subject produce only one example of a particular kind of error. Eighty-three percent of the scores were based on at least five examples of the error type.

\section{APPENDIX Celebrities Used in This Study

Celebrities Used in Experiment 1

Politicians. Past and present members of the U.K. Conservative Party: Jeffrey Archer, Michael Heseltine, Nigel Lawson, Enoch Powell, Norman Tebbitt; and the following: Leonid Brezhnev (ex U.S.S.R. leader), President Gadafi (Libyan leader), Mikhail Gorbachev (current U.S.S.R. leader), Derek Hatton (ex U.K. Labour Party), Neil Kinnock (U.K. opposition leader), Winnie Mandela (South African opposition leader), Caspar Weinberger (U.S. Defense Secretary).

Pop Stars. Phil Collins (ex Genesis member), Bryan Ferry (ex Roxy Music member), Mark Knopfler (Dire Straits member), Simon Le Bon (ex Duran Duran member), Alison Moyet (U.K. singer), Feargal Sharkey (ex Undertones member), Bruce Springsteen (U.S. singer), Sting (ex Police member), Tina Turner (U.S. singer), Paul Weller (Style Council member), Marie Wilson (U.K. singer), Paul Young (U.K. singer).

Sportsmen/women. U.K. soccer players/managers: Kenny Dalglish, Don Howe, Frank McAvennie, Billy McNeill, Charlie Nicholas; U.K. snooker players: Steve Davis, Alex Higgins, Willie Thorne; and the following: Seve Ballesteros (Spanish golfer), Boris Becker (German tennis player), Terry Holmes (U.K. rugby player), Ivan Lendl (Czech tennis player).

Actors/Actresses. U.K. comedy actors: John Cleese, George Cole, Dudley Moore; U.K. TV actresses/personalities: Hannah Gordon, Rula Lenska, Anneka Rice, Pamela Stevenson; U.S. film actors/directors: Clint Eastwood, Orson Welles; and the following: John Forsythe (U.S. TV actor), Richard Gere (U.S. film actor), Tatum O'Neal (U.S. film actress).

\section{Celebrities Used in Experiment 2}

Actors/Actresses. U.S. film actresses: Marilyn Monroe, Raquel Welch, Natalie Wood; U.S. film actors: Kirk Douglas, Henry Fonda, Paul Newman, Gregory Peck; British film actors: Dirk Bogarde, Michael Caine, Sean Connery, James Mason, Roger Moore; U.K. comedy actors: Leonard Rossiter, Peter Sellers; U.K. film or television actresses: Diana Dors, Penelope Keith, Felicity Kendall, Rula Lenska, Pat Phoenix, Diana Rigg.

Politicians. Former U.K. Prime Ministers: James Callaghan, Edward Heath, Harold Wilson; prominent past and present members of the U.K. Labour Party: Tony Benn, Roy Hattersley, Derek Hatton, Dennis Healey, Neil Kinnock; U.K. Alliance Party leaders: Roy Jenkins, David Owen, David Steel; prominent past and present members of the U.K. Conservative Party: Leon Brittan, Michael Heseltine, Nigel Lawson, Enoch Powell, Norman Tebbitt, William Whitelaw; 


\section{APPENDIX (cont'd)}

current U.S.S.R. leader: Mikhail Gorbachev; current U.S. leader: Ronald Reagan; past U.S. leader: John F. Kennedy. Sportsmen/women. U.K. athletes: Zola Budd, Sebastian Coe, Steve Cram, Donna Hartley, Mary Peters; U.S. athlete: Mary Decker; English cricketers: Geoff Boycott, Ian Botham; U.K. soccer players: Kenny Dalglish, Kevin Keegan; U.K. snooker players: Steve Davis, Alex Higgins; U.K. tennis player: Virginia Wade; U.S. tennis players: Chris Evert, Billie-Jean King; U.K. golfer: Tony Jacklin; U.S. golfer: Jack Nicklaus; former U.K. racing driver: James Hunt; former U.K. boxer: Henry Cooper; former U.K. swimmer: Sharon Davies. Singers. U.K. singers: Cilla Black, Kate Bush, David Bowie, Barbara Dickson, David Essex, Gracie Fields, Gary Glitter, Mick Jagger, Elton John, Vera Lynn, Lulu, Paul McCartney, Cliff Richard, Rod Stewart; U.S. singers: Debbie Harry, Barry Manilow, Dolly Parton, Frank Sinatra, Barbara Streisand; Greek singer: Nana Mouskouri.

(Manuscript received September 30, 1986; revision accepted for publication January 31, 1988.) 